\title{
Vaginal Adenoma
}

National Cancer Institute

\section{Source}

National Cancer Institute. Vaginal Adenoma. NCI Thesaurus. Code C40256.

A glandular epithelial neoplasm that arises from the vagina and shows intestinal differentiation. 